\title{
CONCERNING THE NATURE OF POSITIVE LAW:
}

\author{
JEROME HALLi
}

BECAUSE man is a preserver and transmitter of culture, the meaning of elementary scientific terms has changed and deepened from Democritus to Einstein. Because legal philosophers can experience the work of Plato and Aristotle, jurisprudence ought to present a similar progress.

Legal philosophy, however, does not exhibit much evidence of having benefited from the strategic vantage-point thus conferred upon it. This is apparent in many essays concerning the nature of positive law, where it is difficult, if not impossible, to detect any deeper insights than the ancient philosophers had. Instead we are apt to find narrow interpretations by specialists interested in a particular phase of law. Many legal philosophers believe, of course, that the term "positive law" is very ambiguous. They have usually been content to state meanings, ending their analysis with the implication, "You may take your choice." Thus, whatever Kelsen's dialectic actually means, he argues that (a) the definition of positive law is purely a matter of taste and (b) various legal philosophers have had different tastes in this regard-hence there is no better or "objective" determination of the issue. This view is a reflection of the theory that definition is "nominal." 1

On the other hand, the common sense view is that so far as an inquiry is empirical, the definitions used must represent the facts. This approach cannot be dismissed as the common man's naivete. When a scientist defines his terms, he, too, implies that his definitions are descriptive. There is, accordingly, a tentativeness regarding his definitions since his knowledge of the facts is limited and changing. But he certainly intends to represent the existing knowledge in his definitions. His definitions can therefore be challenged as incorrect or inadequate representations of the facts. This same responsibility to the relevant facts should also characterize the definition of positive law. That view is rendered more persuasive when one observes that nominal definitions of positive law stimulate the use of logical and analytical methods and discourage persevering study of the facts with

*This essay was to have appeared in the Max Radin Festselinift. The writer is happy to take the present occasion to pay grateful homage to the distinguished scholar whose career is abundant proof that it is possible to live a great and noble life in legal scholarship and education.

Certain parts of this essay will be included in the writer's Lrmm Law or DeveroCRATIC SocIETY, publication of which is expected in the winter of this year.

$i$ Professor of Law, Indiana University School of Law.

1. "We may define at will those terms which we wish to use as tools in our intellectual work:" Ketsen, General Theory of LaW and State 4 (Wedberg Trans. 1945). 
concomitant revision of definition. They lead their adherents to ignore, or dismiss as irrelevant, facts which challenge their definitions which therefore exercise a prescriptive function.

The problem, at bottom, concerns the "essence" of positive law and so raises one of the permanent problems of philosophic thought. The scholastics, elaborating Aristotle, probed its meaning in detail. An essence, they held, is that which constitutes a thing and distinguishes it from every other thing. It includes both the form and the substance of the thing. The "essence" of law is the first question treated by Aquinas in his Treatise on Law; after determining that, he analyzes the essence of the various kinds of law. ${ }^{2}$

It may be granted that there is apt to be considerable self-deception in any uncritical acceptance of the traditional "essence" of anything. The covert assumption in some of the literature is that the "essence" is obviously present, clear and distinct; and that if we but look and formulate our definitions carefully, we have apprehended and described the whole of our object of investigation. In fact, the quest is always and inevitably only partially successful; certainly no reliance on terms and concepts can alone supply the actual knowledge.

But whatever one may think of traditional explanations of essence, it can hardly be denied that some such notion represents a permanent need. Lacking it, "the mind could never dip twice into the same subject or know its friends from its enemies, and life would be what a romantic philosophy would make it-an idle escape from one error into another." ${ }^{3}$ Thus, if one accepts Dewey's thesis that "anything is 'essential' which is indispensable in a given inquiry and anything is 'accidental' which is superfluous," " one still confronts equally difficult questions regarding what is "indispensable," and why. Perhaps, the best test is that hardly definable but very actual sense of "adequacy," experienced at the end of a thoroughgoing uninhibited inquiry whose findings are accepted by those competent to evaluate them. In any event, it must be concluded that the definition of positive law is not a merely conventional question, a matter of laissez-faire. The fact that highly competent scholars have employed the term in many ways certainly indicates that the discovery of the best definition is not easy. But the least that must be recognized by those who think positive law refers to some sort of existing entity is that the, nature of that entity is not a matter of individual preference.

Philosophizing about and defining positive law occurs in particular

2. In the course of his discussion, he makes it clear that one essence of "human law" (positive law) is "coercive power." St. Thomas Aquinas, The Sumara Theologica, Pt. II, 1st pt., Q. 90, Art. 3, Reply Obj. 3 (Dominican Fathers' Trans. 1915). See KreHL1BAMr, THE METAPHySICAL Foundations OF ThOMISTIC JURISPRUdENCE 92-7 (1939).

3. Santayana, The Reaim of Essence 5 (1928).

4. DEWEY, LoGrc 138 (1938). 
places and times. The existing culture is a conditioner, a limitation on, as well as a stimulus to, the philosopher. Legal philosophers escape neither the fundamental beliefs of their times nor the fabric of fact and event in which their daily lives are immersed. They do not enunciate clear and precise truths whose meaning is full-blown, final, and perfect for all eternity. Their discussions are meaningful only in relation to certain issues, pressing for solution. They were suggested by, and they reflect, various basic perspectives, assumed to be valid. Accordingly, jurisprudence should be interpreted dynamically-as a changing organon in which the meaning of terms shifts appreciably with the movement of the relevant matrix of culture. The legal philosopher does violence to the organon if he intrudes certain meanings merely because they are familiar ones. He must relive the legal philosophies of the past if he is to understand them and develop his own jurisprudence in the light of the accumulated wisdom. To do this requires exacting historical researches and imaginative reconstruction of the actual contexts of the various philosophies.

This process is certainly distant from the traditional practices of legal philosophers, who are wont to read jurisprudence in severe isolation from the concomitant historical situations. They can hardly avoid reading the facts and perspectives of their own times into the jurisprudential abstractions of the past. But that is hardly any guarantee that the philosopher's actual intention or the flow and change of jurisprudential thought are correctly apprehended.

To hold that, if we wish to understand a legal philosophy, we must know the prevailing basic perspectives and the concomitant culture is to imply that there is no such thing as "absolute truth" in jurisprudence and that there is an inevitable falling short in our apprehension of its meaning. These limitations must, however, be sharply distinguished from the denial of any jurisprudential truth or the equating of a philosophy with the man who presented it, indulged in by some psychoanalysts and Marxists who imagine that a biography is an analysis of the subject's philosophy. The insinuation is that economics or instinct is the sole determinant and that the philosophy is only an ideology, understandable on reduction to the above "real" influence.

The present discussion does not accept Marxist epistemology. It does not deny the validity of jurisprudence nor does it depreciate the critical and intuitive methods required to understand it. Instead, this discussion suggests certain additional dimensions that qualify a legal philosophy, while revealing the possibility of gaining new insights into its meaning. For example, any thoughtful person who reads Plato thinks and feels that he is conversing with a kindred spirit; he believes that, for the most part, and barring certain technical problems and transient usages, he understands Plato's thought. The relativist may 
argue that the conditions of the Greek city-state were in large measure very much like those of twentieth century America-hence, that we understand what Plato said to that extent. The twist of the argument here, its reinterpretation there, can defer judgment on the matter indefinitely. What must be said, however, is (a) certain ideas have persisted, at least in Western culture, for thousands of years-and, to some extent, we understand them though we know nothing of the speaker, the place or the circumstances of his discourse (it matters little if one reason for that is a minimal identity of circumstance rather than of mind); and (b) to get the fuller significance of those ideas, the hidden or unexpressed meanings, the precise and particular emphases, we need to reconstruct the social situation, the dominant perspectives, the cultural milieu of the discourse.

The theory suggested above regarding jurisprudence has already been widely adopted in analysis of particular segments of the positive law. Especially in this country ever since Holmes urged that we "think things not words," 5 legal scholars have been sensitized to the actual meaning of rules of law. We now have careful socio-legal researches, reconstructing the life-situations in which various legal formulas were uttered and functioned, in the light of which they are meaningful. "That one is not to clip such terms as "trespass," "larceny," "interstate commerce," ex post facto, etc., from their contexts but must, instead, establish them in their actual habitats has become recognized. The nature of positive law can only be the common core of all the specific positive laws, of certain actual entities. If the above theory is valid with regard to all the specific positive laws, it is true of positive law itself, and thus the road to a better understanding of it is clearly indicated. The same theory implies that jurisprudence, if it is to be "fully" understood, must also be located in living configurations of fact, thought, and feeling. It indicates, finally, the need for a drastic rewriting of the history of legal philosophy since the extant histories typically offer only a stringing-together of plucked and isolated ideas, the mere illusion of adequate presentation.

We can test some of the implications of the above broadly outlined theory in an examination of certain of Roscoe Pound's writings on the nature of positive law. Pound is not selected for special notice because he is the best example of the traditional abstractionism. On the contrary, it is because, though demonstrating an awareness of the importance of the instant problem (Pound has often discussed the nature of positive law), and revealing occasional insights into the significance of

5. Holsies, Collected Legal Papers 238 (1920).

6. Hali, Theft, Law and Soctety (1935). Hamilton and Adais, Tue Powes to Govern (1937); Crosskey, The True Meaning of the Constitutional Prohibition of ExPost-Facto Lazes, 14 U. of Cer. L. Rev. 539 (1947) ; Tiller v. Atlantic Coast Litte Railroad Co., 318 U. S. 54 (1943). 
the concomitant matrix of culture as a qualifying condition (especially in his Interpretations of Legal History), Pound nonetheless, at least in his essays on positive law, has been little influenced by his own suggestive asides.

Pound's major study of the nature of positive law was published in 1912. In this essay, Pound collected numerous definitions of positive law, quoting them with little or no reference to their textual contexts. He held that law had been defined "analytically" by some writers, and that it had been defined by others in terms of reason and justice. He classified the above and various other definitions by reference to his division of the schools of jurisprudence (historical, philosophical, analytical, sociological). Two preliminary difficulties are met.

In the first place, Pound's discussion confuses the imperative aspect of all positive law with legislation. Thus he begins his essay by stating: "A developed body of law is made up of two chief elements, the enacted or imperative element and the traditional or habitual element. The former is the modern element. . . ." s Pound's designation of the imperative element as "modern" reveals that he was not distinguishing the rational from the authoritarian aspect of positive law but, instead, that he identified "imperative element" with "enactment" (legislation) $;^{9}$ apparently he did not recognize that traditional or customary law also and equally has an "imperative element."

Second, Pound confuses "positive law" with "law" used in a wide sense to signify certain common features of moral principles, scientific generalizations, positive laws, etc. This may be inferred from his quotation, in the context of discussing positive law, of various definitions of the general term "law." Thus he quotes Montesquieu, "Law in general is human reason," ${ }^{10}$ and he implies that that was Montesquieu's definition of positive law. But it is clear, on reference to Montesquieu, that the above quotation is from his discussion of the general notion of "law." It was only Montesquieu's way of stating that all law-scientific, moral, positive-is generalization (abstraction) and that generalization is a distinctive mark of a rational being. The implication that Pound raises - that Montesquieu thought of positive law solely in terms of reason and apart from the imperative elementis certainly untenable on reference to other parts of $L^{\prime} E s p r i t$; for example, Montesquieu wrote of "what is commanded or forbidden by

7. Pound, Theories of Law, 22 YALE L. J. 114 (1912). Twenty-three years later he wrote More About the Nature of Law, in Legar Essays m TRmute to O. K. MlcMfunas 513 (1935). This essay is substantially incorporated in Pound, What is Law? $47 \mathrm{~W}$. VA. L.Q. 1 (1940), and the latter is reprinted in Socral ContRol Trrockr LAw, c. 2 (1942).

8. Pound, Theories of Law, 22 YALE L. J. 114 (1912).

9. Id. at 115.

10. Montesquieu, The Spirit of Laws, Bk. I, p. 6 (Nugent trans. 1793). 
positive laws," 11 of "laws relative to the governors and the governed," 12 etc. In the context of such confusion of law, in general, with positive law, Pound's statement that at certain times "the idea of authority and command has disappeared" from jurisprudential definitions of positive law ${ }^{13}$ clouds the major issue which has dominated jurisprudence from Plato to the present time, and thus casts loose the history of jurisprudence from its correct mooring.

Plato is conspicuous in Pound's essay by his absence; yet the Platonic dialogues, Gorgias, The Republic, Statesman, the Lawes and Minos, contain the most important discussions of that issue, forcefully expressed as a type of Interressenjurisprudenz by Callicles and carried to its extremity by Thrasymachus. ${ }^{14}$ Only by reading Plato as a participant in that controversy-and not in terms of abstract lex and itls 16 - can the jurisprudence of the Greeks, especially their discussions on the nature of positive law, be understood. ${ }^{16}$

The issue of "might vs. right" agitated even the earliest Greek writers. It was symbolized by Hesiod in his story of the hawk and the nightingale. ${ }^{17}$ In criticizing his times, he cries: "might shall be right, and one shall sack the other's city. . . . Right shall lie in might of hand. . . ." In In castigating his brother who had made off with Hesiod's share of the paternal estate, the poet implores Zeus to "deal the judgements of righteousness." $10 \mathrm{He}$ lauds those who "deal straight judgements, and no whit depart from justice," and warns those Princes who "with crooked judgements oppress one another, taking no heed of the anger of the gods." And he concludes: "For this law hath the Son of Kronos appointed unto men, even that fishes and beasts and winged birds shall devour each other, since there is no justice in them. But to men, He hath given justice which is far the best." ${ }^{20}$ Thus the poct

\section{Id. at 2.}

12. Id. at 5 .

13. Pound, supra note 8, at 120.

14. ". . . [T] The laws are made by the ruling party in its own interest. . . . By making these laws they define as 'right' for their subjects whatever is for their own interest, and they call anyone who breaks them a 'wrongdoer' and punish him accordingly." PLATO, TuE RLPUBLIC I, 338 (Cornford ed. 1945).

15. Pound, supra note 8, at 120.

16. ". . . The conception of the Power State had become prevalent in all the sophistical theories. . . The thesis that 'might is right' was the simplest, the most plausible and radical formula. It appealed not only to the 'wise men' or sophists but also to the practical men, the leaders of Athenian politics. To attack and destroy this dictum was the principal concern of Plato's theory." Cassirer, The Mytr of tue State 74 (1946). Cf. Koyrte, Discovering Plato 64 (1945).

17. Hestod, Work and Days (Mair ed. 1908).

18. Id. at 11. 187, 191.

19. Id. at $11.8-10$.

20. Id. at 11. $226-8,248-250,276-280$. 
gave imaginative expression to the major inquiry of the later Greek jurisprudence.

Equally significant is Hesiod's thinking of law as emanating from Zeus, i.e., implying the notions of command and power. These ideas are commonly represented in the earliest writing on law; in the Bible, God is the source and the enforcer of law. That notion of law is also found in animistic interpretations of the physical universe: the primitive thought is that natural phenomena must conform to the laws of the gods. It is a long step from that to the idea of fate of the later Greeks, their theories concerning the physical composition of the universe, and their complicated notions of change and permanence. The term "law" persists in science to this day to indicate its original meaning.

Accordingly, although it is probably true that Plato said, "Law seeks [tends] to be the finding out of reality," 21 it is also certain that that, alone, did not represent Plato's view of positive law. In The Republic Socrates speaks of "framing law," "the laws they [rulers] make," "the subjects are to obey any law they lay down," na and of what no one will ever "in his capacity of ruler, do, or command others to do. . . ." "And the heaviest penalty for declining to rule is to be ruled by someone inferior to yourself. That is the fear, I believe, that makes decent people accept power." ${ }^{23}$ In the Laws, Plato spealss of "the patriarchal rule and sovereignty of their parents"; 24 of legislation-Darius "made laws"; of "precepts addressed to him by the legislator." He recognizes the coercive attribute of positive laws, referring to the benefits "the laws . . . will accomplish, partly persuading, and partly when natures do not yield to persuasion, chastising them by might and right. . . ." Again, he notes that legislators "do not temper their power by persuasion, but employ force pure and simple." So too, he knows the dual aspect of positive laws-the hypothesis and the sanction: "Do this, avoid that, and then holding the penalty in terrorem. . . . ${ }^{25} \mathrm{He}$ speaks of "the arbitrary command" as "law pure and simple," of "command, that is to say, the law," and of "the rules which are prescribed for them." $s s$

It is impossible to avoid the conclusion that Plato understood positive law as consisting of prescriptions or commands; and that he under-

21. Plato, Mitros 315 A. (Lamb ed. 1927).

22. Plato, The Republic I, 339 (Cornford ed. 1945).

23. Id. at I, 346,347 .

24. Plato, Laws III, 680 (Jowett ed. 1871).

25. Id. at 695 ; at IV, 718, 722, 719. Specifically he proposes "the law of marriage in a simple form, which may be as follows:-A man shall marry between the ages of thirty and thirty-five, or, if he does not, he shall pay such and such a fine, or shall suffer the loss of such and such privileges." Id. at 721 .

26. Id. at 723; at $\mathrm{V}, 735$. He also writes of the promulgation of the laws. Id. at 722. 
stood the attributes of power and coercion, respectively, in relation to the ruler (sovereign) and as a denotation of the sanction. Indeed, a contemporary definition of law by Xenophon ${ }^{27}$ has encouraged the opinion that the ancient Greeks anticipated the modern legal positivists in all important points. ${ }^{28}$

It is by no means as certain that Plato regarded morality ("justice" or "virtue") as an essential attribute of positive law. There are a number of passages where he seems to take that position, as where he writes of "the sacred and golden cord of reason, called by us the common law of the State"; ${ }^{29}$ and of "that right reason, which the law affirms"; and he insists that the young men "must all agree that the laws are all good and of divine origin." ${ }^{30}$ There are occasional passages in which Plato unmistakably takes the above position- ". . . when those who make the laws miss the good, they have missed the lawful and the law." 31 And in the Minos, which is usually attributed to Plato, Socrates faces the issue directly, taking substantially the same position regarding "law" that he had previously assumed when defending "justice" against Callicles and Thrasymachus. The Minos starts with the request: "Tell me, what is law?" Socrates replies not only that "Law tends to be discovery of reality," just as does "true opinion" 32 but also that " . . . whoever fails to attain reality, fails to attain accepted law." Specifically, he said, ". . . law is a city's resolution" and "an evil resolution cannot properly be a law." "3s The qualification ("properly") suggests that Plato does not insist that all positive laws are ethically valid. Indeed, in numerous passages he distinguishes "true law" from bad law, and the wise from the ignorant, legislator. Thus, he writes, "such laws, in so far as they tended to

27. "All rules of conduct enacted by the sovereign power in the state after due deliberattion are called law." Xenophon, MeMrorabilia $\mathrm{I}, \mathrm{ii}, 43$ (Hude ed. 1891).

28. Calhoun, Greek Law and Modern Jurisprudence, 11 CALIF. L. REv. 295 (1923).

The reason for stressing certain obvious aspects of the Platonic dialogues is not so much that Plato has been neglected in American jurisprudence, although that is unfortunately true, but rather that it is of the utmost importance to lay the foundations of jurisprudence correctly and, in the first instance, by adequate use of the texts. This renders it possible to place the modern legal positivists in their correct setting and significance as well as to deal with the major problems concerning the nature of positive law.

29. Plato, Laws I, 645 (Jowett ed. 1871).

30. Id. at II, 659 ; at I, 634 .

31. Greater Hitpias 284 E. (Fowler ed. 1926).

32. Prato, Minos 315 (Lamb ed. 1927).

33. Id. at 315,316 . Cf. Calhoun's translation, in his INTroduction to GreEs LEGAL SCTENCE 80-1 (1944), especially the following: "Then we must think of law as something fine, and rest our inquiry on the assumption that it is a good? Of course." Cf. Denrostuenes, AgarNst ARistogeiton xxv, 15-8 (Vince ed. 1935) ". . . law intends what is right and honourable and advantageous, and seeks after this, and promulgates it when found in the form of a general command, applying equally to all alike, and this is a law." Quoted, CAl.HOUN, op. cit. stipra, at 83. 
promote virtue, were good"; ${ }^{34}$ and in writing of conquerors, he states: "... nor are laws right which are passed for the good of particular classes and not for the good of the whole state. States which have such laws are not polities but parties, and their notion of justice is simply unmeaning." 35

The most perplexing dialogue is the Crito. The plain inference seems to be that it is right to obey the laws even when they are not good laws. That inference can be disputed on the ground that not the laws, but the administration of them by the popular court, was bad. And this explanation is supported by Socrates' eulogy of the laws and of the benefits they conferred on him. Nonetheless the question persists and it can hardly be doubted that at least one of the positions taken by Socrates is that it is right to obey the laws because they are laws, not because they are just. The moral validity of his decision to submit to the sentence must rest on larger considerations-that orderly government is better than disorder engendered by revolt against particular immoral laws and that, in any event, the laws had been enacted in a democratic process, in which he had participated. While it is thus clear that Plato did not insist that "virtue" is an essential attribute of positive law, it is also evident that he felt strongly in the matter. His apparent indecision was a concession to common linguistic usage as well as an indication, perhaps, that his thinking on law, as elsewhere, was suggestive rather than systematic. ${ }^{36}$

As between Plato and his opponents, there is no doubt regarding Aristotle's position-"without this end [virtue] ... law is only a convention." 37 There are occasional passages, reflecting his synthesis; for example, ". . . the law has compulsory power, while it is at the same time a rule proceeding from a sort of practical wisdom and reason." 3s But it can hardly be said that Aristotle, any more than Plato, definitely maintained that morality is an essential attribute of positive law; e.g., "true forms of government will of necessity have just laws, and perverted forms of government will have unjust laws." "3

That theory was maintained by the Stoics. In Cicero's writing,

34. Plato, Laws IV, 705 (Jorett ed. 1871). Cf. ". . . colonies licl: against ang laws which are other than they had at home, although they have been undone by the badness of them." Id. at $70 \mathrm{~s}$.

35. Id. at 715. So, too, 746.

36. Vinogradoff's assertion that "... the Greels regarded law primarily as the embodiment of justice..." 2 Outrines of Historscar Junisrnude:ice 19 (1922), is an over-statement. That was certainly the preference of the greatest philosophers, but even that can hardly be said to have been true of the population-especially, c.g., after the Peloponnesian Wars. The decisive philosophical step was talsen by the Stoics.

37. Aristotie, Politica 12SOb, 1.9 (Jowett ed. 1921).

38. ARIstotie, Etrica NicOXICHEA 1180a, 1.21 (Ross ed. 1925).

39. ARISTOTIE, Politica 12S2b, 11. 13-4 (Jowett ed. 1921).

40. " $\mathrm{Law}$ is the ruler over all the acts both of gods and men. Law must be the di- 
e.g., what was preference for Plato and Aristotle, becomes essentialto characterize any power norm as "law" is merely to accept "the crowd's definition of law." 41 For Cicero, bad rules, "pestilential statutes . . . no more deserve to be called laws than the rules a band of robbers might pass in their assembly." ${ }^{42}$ The metaphor was restated in St. Augustine's paradoxical epigram - "a law that is not just, seems to be no law at all." St. Thomas Aquinas' definition of positive law as "nothing else than an ordinance of reason for the common good, made by him who has care of the community, and promulgated" ${ }_{43}$ was the crystallization of a long philosophical tradition. But his theory of positive law, just as that of Plato and Aristotle, was in part, a reflection of the social and economic character of his times as well as of certain prevailing perspectives, as will shortly be noted.

It is evident that the formal criteria of law and the fact of power represent the oldest and probably the most primitive insights into the nature of positive law. This must guide interpretations of legal philosophers who sometimes emphasize certain phases of positive law to the extent of ignoring other essential attributes of it-although it is obvious that nothing like the extreme particularism of the modern legal and sociological positivists is found in ancient or mediaeval jurisprudence. Natural law writers sometimes assumed the imperative-coercive aspects of positive law and argued the question that was moot, namely, whether a power norm had to conform to natural law in order to be positive law. Although their jurisprudence is correspondingly inadequate, that was a normal procedure, to be expected of legal philosophers, especially in the formative years of jurisprudence, no less than of other human beings engaged in a debate. On the other hand, modern positivists not only excluded morality from positive law; they hailed that bifurcation as their greatest achievement. They thus joined issue with reference to the nature of positive law. Since no one had argued that command, power and coercion were not essential attributes

rector and governor and guide with respect to what is honorable and base, and thercforc the standard of the just and unjust; for all beings that are social by nature, it directs what must be done and forbids what must not be done." Chrysippus, ON Law, quoted by Sabine and Smith, Introduction to CicERo, ON tHe CoMnonwenltu 22 (1929).

Cf. "And the things which are in the power of a fool are not law." THE Discounses of Epicterus 350 (Long ed. 1877). The editor comments as follows: "The will of a fool does not make law, he says. Unfortunately it does, if we use the word law in the strict sense. . . The strict use of the word 'law' is independent of the quality of the command, which may be wise or foolish, good or bad. But Epictetus docs not use the word 'law' in the strict sense." Id. at 350 n. 11. Cf. infra note 53.

41. Cicero, De Legrbus I, vi, at 319 (Loeb Lib. ed., Keyes, trans. 1928).

42. Id. at II, v, p. 385.

43. Sr. Thonsas Aquinas, op. cit. supra note 2, at Part II, 1st pt., Q. 90, Art. 4 (Dominican Fathers' trans. 1915), reprinted in Fald, Readings in JuRusprudence 28 (1938). 
of positive law, they did not engage in debate on that score. The history of jurisprudence is a debate on other issues, and chiefly on the issue whether the above attributes, though admittedly necessary, are sufficient characterizations of positive law.

Modern Legal Positivism seems largely a restatement of ancient viewpoints-including the exclusion of morality as "ideological"; when the history of jurisprudence has been adequately presented, it may well appear, as Professor Calhoun confidently prophesied, that every important concept of the modern Analytical School had its origin in Greek thought, applied to law by the Romans. "It would, nonetheless, be a serious fallacy to imagine that modern Legal Positivism can be understood as a mere echo of Callicles and Thrasymachus. For, though the expression is similar, the differences in meaning are disclosed when the respective theories are interpreted against the background of concomitant fact and dominant perspectives and needs.

But a careful study of the ancient texts is the first need. Thus, if we examine the context of a sentence plucked from an ancient writing, we may discover that our venerable predecessor was not writing of positive law at all when he asserted "law is right reason" but, instead, of "law," in general. When we scrutinize the text for evidence of his political experience, we may find that the writer was not unfamiliar with tyrants, that he knew or thought he knew the difference between an unjust fiat and a just fiat. And when, in addition, we become acquainted with the relevant history, with the inherited culture as well as the quality of his own times, we may decide that the initial interpretation of the plucked phrase-that he identified positive law and right reason - was quite remote from the ancient philosopher's view.

The ancient texts contain numerous references to historical events, to specific persons and places, and to memories of abuses by rulers, governing classes, and the masses. An adequate analysis of the literature would supplement interpretation of the texts by studies of the relevant history and the contemporaneous social situations.

It is possible here merely to call attention to certain salient facts which suggest the outline of the required supplementary knowledge. 45 In the long, varied Greek history, there was much experience with benevolent tyrants who degenerated into oppressive dictators. ${ }^{40}$ The Greek democracy, except in certain crucial points, was more advanced than our own, expecially as regards the participation of citizens in

44. Calhoun, op. cit. susra note 28 , especially at 300 .

45. Excellent brief accounts are Calmoun, Intaduction to Grees Les.ll Scre:ce (1944), and Jaeger, Praise of Lain, in Interpretations of Monens Legal Prinosorhirs 352 (Sayre ed. 1947). See, generally, JAEGER, PAmEra (1939). There is an abundance of relevant information in BonNer and Sartra, The Adsuristration of Justice froes Honter to ARIstotle $(1930,1938)$.

46. See, e.g., ZnMmern, The Greex Conosonweatith (1911). 
political and legal affairs. It was, indeed, a city of lawyers, where the maxim, ignorantia legis neminem excusat, had a literal meaning and a foundation in fact. Plato wrote in the decline of Athens, after the great wars had seared the optimism and altruism of the polis. The crises, hardships and defeats of Athens had given rise to a general cynicism, a realistic power-politics attitude, articulated by Socrates' adversaries, which set the scene for the birth of jurisprudence. The Greeks were familiar with customary law, codes and legislation. Indeed, Plato and Aristotle carried on researches in comparative law and the functioning of legal institutions that far exceed anything which modern scholars, the victims of current particularisms that debase the significance of such research, are able to imagine, much less undertake. A detailed probing of the relevant cultural facts would be justified if only to emphasize the inadequacy of the extant histories of jurisprudence.

As matters stand, we know there are many questions that remain unanswered-apart from the over-all lack of intimate apprehension of the changing nature of law and of the paralleling jurisprudence. Precisely what were the factual references of the Platonic dialogues, of Aristotle, the Stoics, St. Thomas, etc.? To whom were they addressing themselves? What were the particular issues they confronted? What were the social problems dealt with in the positive laws of the time? How did it happen that Plato and Aristotle preferred certain theories of the nature of positive law, but still accepted common opposing ideas prevailing at the time, while the Stoics, St. Augustine and the scholastics felt free to cut entirely the bond of common usage? At present, we have only a few suspicions regarding these and many other important questions of legal philosophy. Our understanding of the nature of positive law is correspondingly limited.

A resulting major hazard in any jurisprudential inquiry is a confusion of the nature of positive law with what legal philosophers have said about that. But the two must be carefully distinguished. Thus a scholar might be "describing" law in terms of ethics simply because the ethical side of law is the burning issue of his times. A political theorist, a Stoic or a descendant of the Stoics, may discuss "equality" as an essential element of a just polity and even of positive law. But a glance at the contemporaneous political facts reveals that he was indulging in utopia. We need, accordingly, to keep an eye on both, gleaning ideas and interpretations from jurisprudence and correcting them by reference to the historical facts. If our quest is to determine the nature of positive law, our final concern is not, what did various writers think positive law was or is or should have been; but rather, what has been, what is, positive law?

If positive laws are integral phases of a complex cultural process, a fuller understanding of the nature of positive law depends upon a sound theory of history. This implies that positive law has changed; 
and that a significant index of its nature and its changes can be derived by reference to important differences in the general historical process. Thus a necessary prerequisite to the full derelopment of a theory of positive law is a cultural history of positive law from the ancient Greels to our own times. Such a history would embody theories of social change; and it would probably emphasize recognized eras and dominant forces from the Greek city-state to our own times. Against the background of such a legal history of Western civilization-a laboratory for the speculative mind-the legal philosopher could construct his jurisprudence, especially his theory of the nature of positive law.

We come directly to a principal datum in such a history when we confront the fact of democratic law. ${ }^{47}$ Democratic law, at least in its present proportions, is of recent origin, coinciding with the rise of the modern democratic state in the nineteenth century. The ancients thought and acted in terms of a restricted citizenry. The ideal of the Middle Ages was satisfied by the wise Prince - the benevolent despot. ${ }^{43}$ Thus, although the principle of equality is prominent in jurisprudence from the Stoics on, the facts of servile status and lack of participation in the political life stand out in marked contrast to the theory. It is true, of course, that the ideal of unrestricted participation by the entire normal adult population has not yet been completely realized. But the principle of political equality has been realized to such a substantial degree in present democratic society as to differentiate the representative positive law markedly from that of earlier times. The crucial facts center in the process of law-making, in the broad sense of the term. As against the Greek process of law-making, ours is inclusive. As against the mediaeval process, ours is much more sharply differentiated-the discovery of law by the potentially whole population participating in free discussion, self-rule as against benevolent despotism.

It is possible to argue the question whether democratic law is something new so far as its value attribute is concerned or whether it represents merely the evolution of earlier positive law which "conformed to natural law." Given the present perspectives of modern democratic society, what must be said is that there is certainly a very great difference between a rule which, though well motivated and good for the subjects, is nonetheless laid down for them, and a rule which citizens discover for themselves in free inquiry and debate. There may be approval of the former and even consent to it; but it is not self-rule established in a process in which all normal adults are free to participate.

To think of the suggested theory of democratic law as a questionable

47. Hald, The Living Law of Dexocratic Soctety (1949).

48. See St. Thomas' definition of law in the text sipra at note 43, and his Ori Tar Goternance of Rolers (Phelan trans. 1938). 
attribution of the process whereby a law originates to the law itself reveals the strong imprint of the prevailing abstractionism. For it can hardly be questioned that there is actually a vast difference between a law adopted in the democratic process and a formally identical rule promulgated by a dictator or in an oligarchy. It is possible, of course, that certain factual conditions are so universal that the same formulas not only exist in various countries but are also actually equivalent rules. But it is equally clear, indeed, it is much more likely, that im. portant differences are to be found despite the identity of terms. Is an identically phrased rule concerning bigamy the same thing in the United States and in Kemal's Turkey? Do statutes removing disabilities of married women comprise identical actualities in those respective cultures? To ascribe the differences to extraneous matters such as enforcement is to beg the question. ${ }^{49}$ Certainly the method of democracy is not the resulting laws. But, just as the Stoics held that positive law partakes of the quality of natural law, so here it may be said that democratic law partakes not only of valid ethical principle but also of the distinctive values of the democratic process. Certainly the legal philosopher, from his present vantage point in history, how* ever he discourses on it, must include the attributes of democratic law in his analysis. His interpretation of the nature of positive law must take account of the undeniable fact that democratic law exists.

One who seeks, accordingly, to discover the nature of positive law is confronted on the one hand by the rigorous, restrictive analysis of the modern legal positivists and on the other hand by the confused but occasionally very suggestive interpretations of the various sociological schools of jurisprudence. The procedure necessary to advance the solution of the problem is thus indicated.

In his later essays, Pound reported the various interpretations of "positive law" which he recognized as significant. He thus came to conclude that positive law means (1) legal precepts, which include rules, principles, conceptions, and standards; (2) the legal order; (3) the judicial and administrative process; and, apparently, (4) "received techniques" and (5) "received ideals." Pound simply placed these various meanings side by side. He has thus provided, at best, only an unrelated mixture of assumed attributes of positive law and of the principal interests of various legal philosophers. He has not provided any synfhesis, any unifying theory, which would permit him to harmonize and use what he culled from the literature.

What is required is a general theory of knowledge adapted to legal experience. That which would support the writer's viewpoint is opposed, on the one hand, to Platonic bifurcation-with the essence of

49. Plato and Aristotle noted that positive laws differed in relation to the form of polity. But they did not interpret the nature of positive law in terms of that suggestion. 
all things perfectly, universally and eternally fixed in "objective ideals," and fact relegated to a mere copying of those models. Nor, on the other hand, can we assume, as does traditional realism, a complete external reality which has its impact on a merely passive impressionable mental clay. What we find, if we do not prejudge the problem, are interactions of mind with environment, together with an awareness and recognition of such interactions. Inseparably woven into certain of these interactions (coalescences or transactions or socio-legal complexes) are positive laws and our thinking and talking about positive laws. The validity of a jurisprudence must be tested by this experience. ${ }^{50}$

While some of the sociological schools of jurisprudence, despite serious limitations, provide numerous insights that are helpful in constructing an adequate theory of the nature of positive law, Legal Positivism remains the major obstacle in the way of attaining that objective. The central fact is that Legal Positivism does not merely distinguish; it sharply separates rules of law, ethical principles, and scientific generalizations. Its analysis therefore comprises a particularism which is not merely inadequate but untrue and misleading. ${ }^{51}$

Legal Positivism holds that rules of positive law are prescriptions whereas scientific generalizations are descriptions. Accordingly, although a single "opposing" phenomenon would invalidate a scientific generalization, rules of law continue unimpaired regardless of violations; indeed, that is to be expected-for example, there would be no point in legislating that all persons must eat enough food to keep themselves alive. But it is possible to state scientific generalizations in the form of propositions that are normative, e.g., if you want to make water you must add $\mathrm{O}$ to $\mathrm{H}_{2}$. The objection to casting scientific laws in a prescriptive form amounts to a pointing to facts that operate regardless of anyone's volition. But those empirical grounds are not recognized by positivists as being relevant to the "pure" nature of rules of law.

If a rule of law is viewed as a hypothetical judgment, it is nonetheless true that each of the clauses comprising such a judgment includes an implied factual generalization, indeed, several of them. Thus the "circumstance clause" implies or incorporates a description of the fact that human beings exist and that they behave in certain ways-that they kill other human beings, take things from their possession, burn the houses they inhabit, fail to deliver merchandise they promised to deliver, or operate automobiles that damage others' persons and property. The sanctions likewise incorporate references to the exist-

50. The writer has discussed some of the phases of this problem in Intcgrofize Itsrisprudence in Interpretations of Miodern Legal Philosopams 322-30 (Sayre ed. 1947).

51. See id. at 317-22, for additional criticism of Legal Positivism. 
ence of human beings and the official doing of certain undesired things to them-killing or imprisoning them; taking things (property) from some of them and giving it to others (judgment creditors). The incorporation of the references to these facts in rules of law implies the recurrence of the facts, accepted theories of "causality" and other criteria of factual happenings, familiar in the sciences. The legal rules are no more valid than the factual generalizations they incorporate; instead of rules of law and scientific generalizations existing in separate worlds, the one includes the other.

The legal positivist cannot deny the above references to fact, callsality, and similar denotations in rules of law. He must concentrate on the idea, the significance of rules of law-the scientific generalization, he insists, describes recurrent facts, whereas the legal rule is a norm, prescribing, etc. But is it not apparent that this rigorous separation is largely verbal (practically important, to be sure, as a classificatory device for lawyers) rather than an adequate plumbing of the nature of legal rules? For, clearly, the recurrence of facts, the causality attributed them and the representation of these in rules of law are part of the significance of those rules. In short, rules of law are generalizations about facts, they are a way of dealing with facts; hence it is indefensible to concentrate entirely on the legal abstractions in disregard of the facts.

There is another way of noting that rules of positive law "partake" of the quality of scientific generalizations. Thus, there is certainly some truth in the position of the Historical School that positive laws are discovered, not made. The consensus that legislation cannot be arbitrary if it is to be effective implies that there are external conditions that must be accepted, within limits, and also that some laws "fit" those conditions while others do not. Thus popular attitudes, the economic conditions, and other various factors which Montesquieu and succeeding legal sociologists have emphasized are relevant to the nature of rules of law. They suggest various necessities significant for and in positive law, and also a common quality of both rules of positive law and scientific generalizations, a relationship to fact. Positivism has erred in ignoring that as well as the descriptiveness of legal prescriptions.

When positivists insist that we must eliminate factual and "ideological" elements from positive law in order to distill the "purely legal" product, they mean that we must confine our interest to certain criteria, i.e., to form and to the fact of power. In rejecting that position, one need not depreciate the importance of critical-formal analysis or of its product-certain notions which are common to the positive law of all societies and polities. The fallacy lies in the insistence that the distinctive structure and the fact of power exhatist the nature of positive law and that everything said beyond those 
criteria are alien to positive law or, at best, additions to what is already, without them, positive law.

Many writers have criticized this "narrowness" of Legal Positivism, sensing that there was more in positive law than interested the exponents of that school. Others have recognized the reactionary implications of Legal Positivism; because of its honorific connotation, they dislike the restriction of "law" to a structure representing only the fact of power. If the positivists' claim that they were only adhering steadfastly to the canons of Science were valid, one might disregard the above criticism. But it is precisely because the legal positivists are not scientific, in any fundamental sense of the term, that their theory must be rejected.

Before examining the merits of that issue it is worth noting that Legal Positivism had its modern origin in the monarchical State, ruled by kings claiming divine right. Yet it flourished and gained wide acceptance in the golden age of liberalism and the rise of modern democracy, thus warning us against simple historical "explanation" of any jurisprudence. It is nonetheless a defensible thesis that the meaning of law which suited the taste of the absolute monarch survived and prospered in the soil of liberalism and democracy because of its practical utility, including its implementation of the "rule of law" not because it was sound theory. The anachronism is further explainable by reference to the political facts and practices of liberalism and democracy which rendered positivism tolerable. The point may be underlined if we ask: what would have happened to Legal Positivism in the eighteenth and nineteenth centuries if, instead of liberal democracy, tyranny and oppression had characterized the contemporaneous governments and the "rule of law" had been merely the fiat of dictators? In short, the very aspersion which legal positivists frequently cast upon opposing philosophies-that they are merely ideological defenses of the status quo-is rather obviously applicable to the origin of Legal Positivism, itself, as is manifest in Hobbes. The present issue -including the inadequacy of Legal Positivism-cannot, however, be resolved by such simple arguments which, if pushed far enough, only terminate in an irrationalism that renders any discussion meaningless.

It is nonetheless important to understand that Legal Positivism was a phase of a certain cultural situation-Statism, logicism, a certain economic utility, rule of law, specialization, and so on. But it is essential to supplement the insight, thus derived, by the linowledge of positive law in the long eras prior to modern Statism, as well as by that of current democratic law. This procedure is certainly quite different from that implied in the mere notation that the resurgence of dictatorship has brought Legal Positivism into ill-repute.

One can go farther and show that Legal Positivism falls far short of relevant scientific requirements. For, although the positivists are 
right in the minimal legal attributes they affirm, they are in error as regards much of what they exclude. If, as the positivists insist, the criteria of validity must be those of science, then they surely can not object if their theory is tested by reference to fact.

Suppose we examine norms which everyone recognizes as rules of the common law of crimes. We must certainly say about them what the positivists say, namely, that they are exhibited in a distinctive structure, signifying hypothetical judgments, and that the sanctions represent the maximum physical force in the society, which operates regardless of the consent of the convicted person. But is that all that one must say about the criminal law, as law? Is anything else stated about the nature of criminal law mere ideology or gratuitous additions to what is already law? On the contrary, as was shown above, rules of law bear a certain relation to fact and they also include descriptions of fact. But, more than that, the rules of law are, themselves, a kind of fact. They comprise a thing that is, in part, external to the human actor, which affects his conduct just as surely as did the rock Dr. Johnson kicked in his refutation of the Idealists. The positivist distinguishes rules of law from their effects and that is, of course, a necessary distinction. But he refuses to draw the inference that it takes fact to produce those effects and that, therefore, rules of law are a kind of fact. An abstraction does not influence conduct merely by being criticized. But when the idea is filled with the flesh and bones of social fact it becomes an influence on actual conduct, a cause of certain effects, a kind of fact. ${ }^{52}$ The positivist's refusal to recognize that is certainly not dictated by any canon of empirical science or the functioning of a mind bent on knowledge. It is rather the sophistication of idealist epistemology, remaining aloof from normal scientific inquiry.

What must be said next is that many rules of law are somehow wrapped in feeling, and that we do not understand the rules unless we take account of the affective states that sustain them. Of course, the rules of law represent human thoughts; but when those thoughts concern social harms, they coalesce with attendant degrees of feeling. That is the sort of being man is; hence it requires some effort to distinguish the thought from the feeling in order to dissect the former. But the distinction and dissection do not change the actual character of positive laws.

Because of the dominance of Legal Positivism during the past two centuries the question will naturally arise: "What about laws that are obsolete or unknown or that represent only the attitude of a dictator?" But we must not permit ourselves unwarily to assume the validity of

52. "It [law] is as definite a fact as any observable phenomenon could be." Radin, Ex Facto Ius: Ex Jure Factum in InTERPRETATIONS of MODERN LEGAL PuILOSOHHik's 578 (1947). 
the positivist's thesis; we must be on guard against such usage of the term in issue. We must remain steadfast in the position that, since the issue is whether certain entities are laws, it is not legitimate to assume that they are laws. They are admittedly power norms, stated in the distinctive structure of positive laws. ${ }^{53}$ If, as we probe the full history of legal institutions, we find that the bulk of the most significant power norms are integrated in them, it becomes necessary to understand positive law as something essentially more than the positivist discovers.

The solid, permanent, pervasive facts of customary law suggest the most obvious refutation of Legal Positivism. For when legal positivists take refuge behind the tenuous facade of "pure" law, simultaneously claiming adherence to Science, one need but point to customary law. In opposition to Maine's supposition that themis and patriarchal absolutism preceded customary law are the more persuasive theories that man is known only in society-and that ubi socielas $i b i$ ius. In advanced societies, codification and legislation, involving dramatic processes and initiatives, are apt to throw one off the path of the abiding character of customary law. But only an arbitrary exclusion of fact can imply that the rules of customary law are merely power norms. The norms of customary law are integrated in the living conduct and feeling of the community. Their origin and existence, in part, depend on spontaneity-on lack of control from above. Moreover, since the process whence customary law issues is to some degree rational, and not solely routine or accidental-as a caricature of the rule of precedent implies-it must also be recognized that customary law is, to some degree, "right law"; emotion and reason interact so that what is emotionally approved is apt to be ethically valid - though that, of course, is not always true. In short, if we wish to know the nature of positive law, we must take account of the nature of customary law. And if we can be certain of anything in jurisprudence, we can be certain that customary law is not composed merely of "pure" rules or sheer power norms and nothing else.

Accordingly, we can and must say that certain norms not only satisfy the positivist's criteria and are also cultural facts; we must, in addition, recognize that they embody certain ethical principles. This implies that value judgments have an "objective" existence and that they are embodied in certain rules which, having met the additional tests, stated above, are positive law. Thus the category here insisted on-that of Value can be attributed to primitive law as little more than emotional adherence and lack of deliberate interest in the ethical

53. "The capricious orders of a crazy despot may be laws according to Austin's definition until they are revoked; but if so, it is the worse for the definition." Pontocr, EsSAYS IN JURISPRUDENCE AND ETHICS 50 (1882). 
validity of the rules. The latter comes when communities become aware of norms and begin to speculate about them; and this culminates in Natural Law thinking-a product of an advanced culture. Democratic law represents, in addition, a radical progress in political values. ${ }^{54}$

Reverting to the challenge that some "laws" are admittedly unjust, we may now point more significantly to the facts that must control the definition of positive law, especially to customary and to democratic law. And we may observe, next, that the injustice of certain norms is irrelevant to the validity of the theory presented here, though, of course, the range of its incidence is involved.

It is obvious that any functioning system of power norms includes rules which can not be defended on moral grounds or whose defense on such grounds must rest on considerations similar to those noted regarding the Crito, rather than on the ethical validity of the rules themselves. A large part of torts is questionable on moral grounds. There is the imposition of strict liability in certain punitive sanctions. There is the rule that a will must be witnessed by a specified number of persons, and the like. There are archaic rules, occasionally exhumed by lawyers intent on profiting from the lack of any principle of des* uetudo. Beyond such immediate data is the common tension between the inadequate justice of a generalization and the perfectly individualized justice, which presents one of the persistent problems of both aclministration and jurisprudence. And there is, finally, the falling short of the "minimal" morality in law from that plenitude of moral insight which the Puritans recognized as the realm of grace.

These facts raise doubt (if we conform to the prevailing mode of thought) regarding the thesis that moral validity is an essential attribute of positive law. But the instant problem imposes no compulsion to prove that all recognized power norms are rules of law. The desideratum is, instead, to discover the theory which is most responsive to the soundly distinguished facts and qualities of all the power norms known to us-a qualitative, historical estimate. This requires us to distinguish the practical from the theoretical meaning of positive law. For the practitioner; the entire question of the nature of law is usually insignificant. The lawyer's thinking is in terms of recognized power norms, although that is by no means true of the layman in his daily conduct. We are diverted from the path of knowledge by our addiction to the practical, professional problems. We are diverted by the fact that our laws are written. The written sentences tend to dominate the thinking of bookmen and thus to emphasize the structure of law rather than its actualities. What we must try to do is to think of positive law existing outside the books. Imagine that a fire has con-

54. HaIs, op. cit. stepra note 50 . 
sumed all the books and records-the positive law would nonetheless continue to exist. That may help one to think of law as an actual entity in social life, as cultural fact, as a lind of factual-ralue experience. This does not imply that a valid jurisprudence can be constructed in isolation from practice-in the wide sense of the term. Indeed, it is that very indifference to fact which is at the root of the positivist fallacy. But it is one thing to create a theory in intimate relationship to practice and quite another to construct one designed for the utility of practitioners.

A mere inquirer, an unmotivated or, rather, a singularly motivated truth-seeker, cannot dispense with fact and value as essential aspects of positive law. The long history of customary law, with hardly any beginning and without any end, confronts him. The positive law of modern democratic society confronts him. The acid test of the conflicting theories of law is-which fits fact and experience, past and present, better? Certainly, as a matter of fact, as a fact of history, the positive law of most societies through the ages has been more than power norms. Not scientists, but the sciolists of the ivory tower, the minute philosophers, fail to comprehend-or at least to describe-the actual thing that has been and is positive law. They do not begin to provide the insight of the twentieth century mind into the life-like, changing qualities of functioning legal norms. We need to go far beyond Legal Positivism to satisfy such needs as persist and will not be satisfied by the dogma that everything except the formal structure of law is extraneous to its nature - a mere "parallel" process or "ideology." The positivist ignores the facts and values that characterize positive law in order clearly to expose the definite anatomy of power norms ("dog law"). Because there is something of that in every positive law ("human law"), the artifice is not to be wholly depreciated.

There are, of course, serious problems of terminology to be considered by those who wish to communicate their understanding of positive law as a cultural fact. A relatively simple procedure might seem to be to state the formal-power attributes in a minimal definition of positive law; and to contrast that with (1) actual law integrated in the institutions, and (2) ethical actual law, the highest type being democratic law. This terminology has the "advantages" claimed by the positivists-it avoids the difficulties met in dealing with the actual power norms of the various types of culture; and there is the advantage of conformity to traditional usage and to the familiar language of the practitioners.

From the writer's viewpoint, however, the practical advantages must be rejected. They imply acceptance of the positivist theory, and constitute the very hazards which cloud thinking on the subject. The plain issues are: does the positivist ignore the factual and qualitative aspects of law? Does he take account of the history of positive law? 
Which terms are best suited to the needs of theory and research? Customary law and the positive law of democratic societies, alone, indicate decisive answers to those questions. The latter law provides the legal philosopher with the "perfect sample," the datum which illuminates the meaning of less significant, and sometimes insignificant, specimens of law.

Whether one agrees with this estimate of the law of modern democratic societies or not, it is undeniable that the legal philosopher, if he wishes to be scientific, must deal with the actualities comprising positive laws. His theory regarding the nature of positive law must be tested by reference to the attributes of positive law as revealed in legal history. The difficulties of communicating his insight into these actualities are, of course, much greater than the problems to which the positivists confine themselves. But the linguistic difficulties should neither divert our analysis from the significant data nor discourage efforts to communicate our present insight. Indeed, the signs are all about us that the principal problem confronting legal philosophers is precisely that of transcending Legal Positivism and achieving a jurisprudence that is adequate in the light of legal history and juridical experience.

For those whose bent of mind requires appreciation of the actuality of law, law as an integral part of the "historical event," is a basic insight. And, although the meaning of historical events can and, for some purposes, may, be reduced to very simple uniformities, there is no point in deceiving oneself regarding the adequacy of the corresponding, representative formulas-when the fullest possible undorstanding of positive law is the objective sought. We cannot escape the fact that positive law is part of an historical changing process. We must say, accordingly, that positive law has had such and such particular attributes in certain places and times, and that its common formalpower attributes are those stipulated by the legal positivists. But we cannot be satisfied with that. We cannot therefore avoid the rigorous task of trying to understand an object whose changing fluidity includes both fact and value. Moreover, although the common attributes of positive law are few in number (formal, factual, and qualitative), an analysis confined to generalizations regarding those attributes would not suffice. One need only advert to primitive times, classical civilization, feudalism, the Renaissance, the Reformation, the Commercial and Industrial Revolutions, and the modern democratic state, and consider some of the distinctive characteristics of the positive law of those periods to understand the difficulties of adequate description of the nature of positive law. Indeed, these eras are merely the most salient, convenient pegs on which to hang various segments of a continuously existing, actual legal structure, a distinctive cultural fact, in process of change. 